\title{
Adrenal Pheochromocytoma Treated With Stereotactic Body Radiation Therapy
}

\author{
Iván D. González ${ }^{1}$, Alexandra Vallejo ${ }^{1}$, Eduardo Guerrero Lizcano ${ }^{2}$, Alexandra Pabón Girón ${ }^{3}$ \\ 1. Radiation Oncology, Universidad Militar Nueva Granada, Bogota, COL 2. Radiation Oncology, Instituto Nacional de \\ Cancerología, Bogota, COL 3. Medical Physics, Instituto Nacional de Cancerología, Bogot, COL
}

Corresponding author: Alexandra Vallejo, vallejoalexandra1@hotmail.com

\begin{abstract}
Pheochromocytoma is a rare neuroendocrine tumor arising from chromaffin cells in the adrenal medulla. In most cases, it is benign and tends to remain localized. However since it leads to the development of cardiovascular disease, it is associated with high rates of morbidity and mortality. Treatment options include medical, surgical, or ablative measures, which often adequately control the disease. Primary pheochromocytoma is conventionally treated with external beam radiation therapy (EBRT), while stereotactic body radiation therapy (SBRT) is preferred for cases with metastasis. However, literature regarding the use of SBRT for the treatment of primary disease is scarce. This case report describes a patient with an inoperable primary adrenal gland pheochromocytoma who was treated with SBRT, resulting in adequate symptomatic control during clinical follow-up.
\end{abstract}

Categories: Endocrinology/Diabetes/Metabolism, Radiation Oncology, Oncology

Keywords: pheochromocytoma, symptomatic control, metanephrines, sbrt

\section{Introduction}

Pheochromocytoma is a neuroendocrine tumor arising from chromaffin cells in the adrenal medulla. In most cases, it is benign and tends to remain localized [1]. It is considered a rare tumor with an incidence of two to eight cases per million inhabitants. Although it is a benign tumor, it is associated with high mortality and morbidities such as arterial hypertension and cardiovascular disease due to hypersecretion of catecholamines and metanephrines [2].

Germline mutations in susceptible genes account for approximately $40 \%$ of the cases. These include mutations in the VHL gene that codes for the von Hippel-Lindau protein. which possesses ubiquitin ligase 3E. It inactivates hypoxia-inducible factors that are involved in angiogenesis [3].

Received 09/06/2020 Review began $10 / 05 / 2020$ Review ended 12/30/2020 Published 01/03/2021

\section{() Copyright 2021}

González et al. This is an open access article distributed under the terms of the Creative Commons Attribution License CC-BY 4.0., which permits unrestricted use, distribution, and reproduction in any medium, provided the original author and source are credited.
Von Hippel-Lindau disease is an autosomal dominant syndrome that affects 1 in 36,000 births per year. Unilateral or bilateral pheochromocytoma can occur in $10-20 \%$ of these patients; the mean age at diagnosis is 30 years, and approximately $5 \%$ develop metastatic disease at some point [4]. Overall, the 5 -year survival rate in benign cases is 90 to $95 \%$; however, malignant pheochromocytoma prognosis is poor, with a 5 -year survival rate reported at 34 to $72 \%$ [5]. The classic triad of symptoms includes diaphoresis, headache, and tachycardia associated with hypertension and elevated catecholamines or metanephrines. Both plasma-free and 2-hour urinary fractionated metanephrines have more than a $90 \%$ sensitivity to pheochromocytoma diagnosis [6]. In addition, since $75 \%$ of these tumors are located in the adrenal gland, computed tomography (CT) or magnetic resonance imaging (MRI) of the abdomen or pelvis are appropriate imaging tools. On MRI, the classic imaging feature for pheochromocytomas is a "lightbulb bright" lesion with a solid hypervascular component in the T2 sequence. In T1 images, pheochromocytomas are typically isointense to muscle and hypointense to the liver. In the case of necrosis or hemorrhage, appearances can be quite variable [7].

There are several therapeutic strategies to treat this type of tumor. If the patient is asymptomatic, clinical follow-up can be done without therapeutic intervention. On the other hand, when the patient does have symptoms, multiple therapeutic approaches can be used for adrenal lesions, including systemic therapies, surgical treatment using open and laparoscopic adrenalectomy, Iodine-131, meta-iodobenzylguanidine (MIBG), or percutaneous radiofrequency ablation [8-9]. Additionally, antihypertensive medications are often required to prevent a catecholamine crisis and tumor lysis.

Using external radiation therapy to treat metastatic pheochromocytoma is controversial. Retrospective cohorts have shown that stereotactic radiosurgery/stereotactic body radiation therapy (SRS/SBRT) at a dose of 21.9 Gy provides symptomatic control or imaging stabilization at $81 \%$ and $87 \%$, respectively [10]. Radiosurgery allows high doses of radiation with low toxicity to adjacent normal tissue to be administered [11]. The suggestion is to use SRS /SBRT in tumors less than $3 \mathrm{~cm}$ and normofractionated external beam radiation therapy (EBRT) for larger lesions [12]. The majority of reviews in available literature only partially document patient characteristics, radiation techniques, and results, making it difficult to establish a uniform treatment to follow and specific patient characteristics. There are multiple therapeutic approaches for 


\section{Cureus}

adrenal gland lesions, such as stereotactic body radiotherapy/radiosurgery (SBRT), which provide an additional therapeutic option for patients with contraindications or who are refractory to the abovementioned standard treatments. SBRT allows a high dose of radiation to be delivered with a rapid drop in the dose gradient to adjacent soft tissues.

Holy et al. analyzed effectiveness in patients in Germany and reported on 18 patients (13 with curative intent and five with palliative intent) treated with SBRT in doses that varied between $25 \mathrm{~Gy}$ in five fractions, 24 Gy in eight fractions, 36 Gy in six fractions, achieving a BED (Biological Equivalent Dose) of 37.5 Gy to $57.6 \mathrm{~Gy}$. A local control rate of up to $77 \%$ was achieved [13].

The objective of this case report is to share the experience our institution had in adequately controlling the symptoms in a patient diagnosed with adrenal pheochromocytoma in whom other therapeutic alternatives were contraindicated. The patient was treated with SBRT, an innovative technique that delivers high doses of treatment to a small target while avoiding high doses to organs at risk.

\section{Case Presentation}

A 27-year-old patient was diagnosed with von Hippel Lindau disease and had associated pathologies such as cerebellar hemangioblastomas treated with resection in June 2010, renal cell carcinoma diagnosed and treated with right nephrectomy in 2010, and a benign intra-adrenal pheochromocytoma (paraganglioma) on which a right-adrenalectomy was performed in 2011. Subsequently, the patient was treated with Sunitinib which was suspended due to cardiac toxicity in 2016. That same year a new right adrenal lesion appeared during clinical follow-up. In 2018 serum markers were found to be elevated, with free metanephrines in the plasma present at $110.8 \mathrm{pg} / \mathrm{mL}$ (normal value: $0-90 \mathrm{pg} / \mathrm{mL}$ ) and free normetanephrines in the plasma present at $381.2 \mathrm{pg} / \mathrm{mL}$ (normal value: $0-180 \mathrm{pg} / \mathrm{mL}$ ). $\mathrm{mL}$ ), with a subsequent elevation of blood pressure requiring an increase in the dose of antihypertensive medications (enalapril, spironolactone, and doxazocin). In September 2018, a 24 x 19 mm hypermetabolic nodule located in the right adrenal gland was documented by positron emission tomography-computed tomography (PET-CT) (Figure 1). The case was discussed in a multidisciplinary meeting with the urology, oncology, interventional radiology,

endocrinology, and radiation oncology departments where the conclusion was reached that the patient had no surgical choices due to comorbidities and technical difficulties presented in the previous surgeries, in addition to an associated coagulopathy. When evaluated by a radiation oncologist, the patient was on antihypertensive medication: $2 \mathrm{mg}$ doxazocin at night, $5 \mathrm{mg}$ enalapril daily (discontinuous intake), and 25 $\mathrm{mg}$ spironolactone daily. At that time, the patient was symptomatic with a headache rated $7 / 10$ on the visual analog scale and poor control despite medical management.

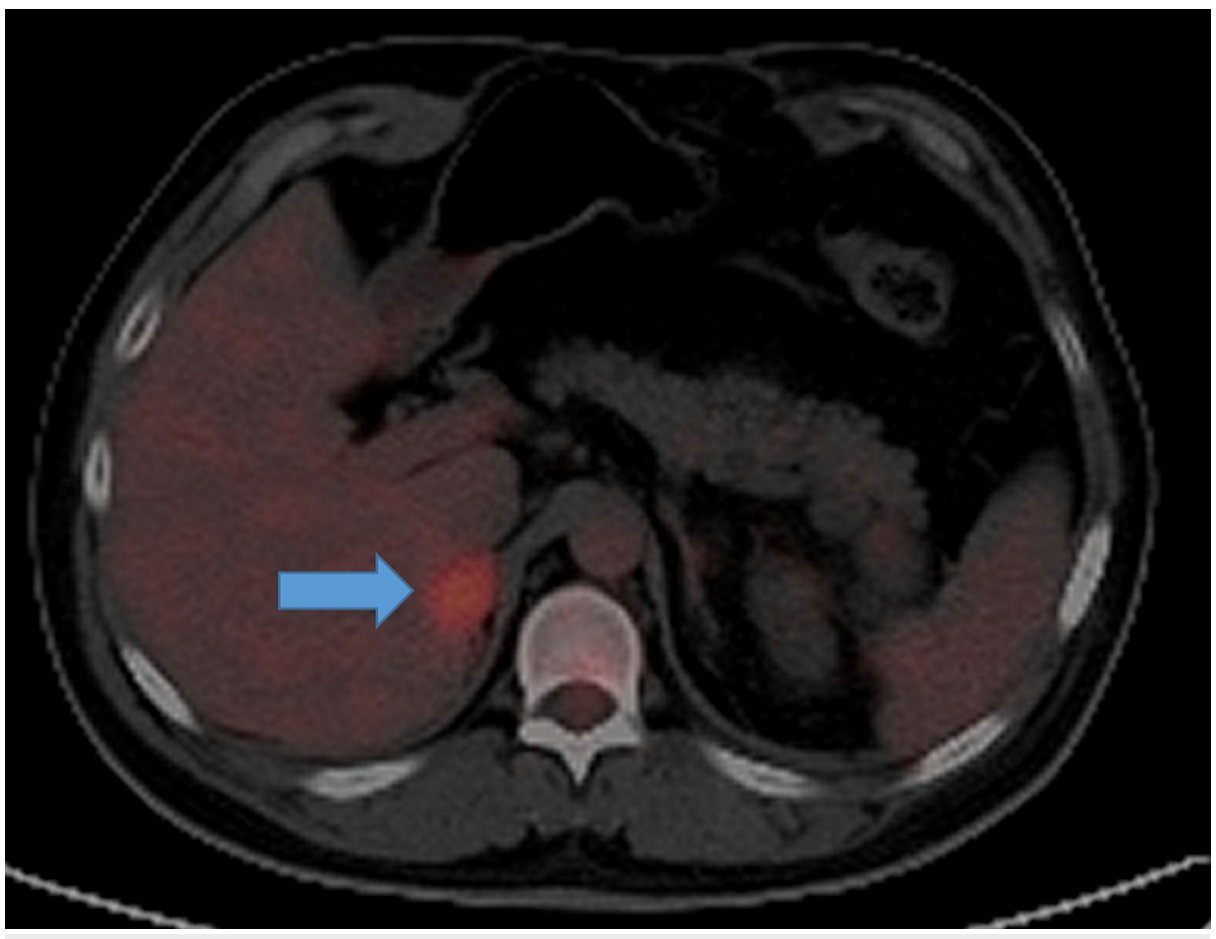

FIGURE 1: Positron emission tomography following 18F-FDG uptake

An infiltrative, hyper-metabolic nodule dependent on the right adrenal gland can be seen in the image. It measured $24 \times 19 \mathrm{~mm}$ and exhibited a soft tissue density and an SUV $\max$ of 6. 8 .

SUV $_{\text {max }}$ : maximum standardized uptake value; 18F-FDG: 2-deoxy-2-fluoro(fluorine-18)-D-glucose. 


\section{Cureus}

The medical board considered treatment using SBRT in fractionations of $800 \mathrm{cGy}$ up to a total dose of 2400 cGy, which was to be delivered to the PTV (planning treatment volume = gross tumor plus a margin) to achieve local and symptomatic control. To delineate the tumor a 4DCT scan was performed after immobilizing the patient with an abdominal compressor and a Vac-lok ${ }^{\mathrm{TM}}$ device. Scanning was done in four respiratory phases followed by reconstruction of the images by $4 \mathrm{D}$ simulation of the 4DCT data. To delineate the tumor we fused the abdominal magnetic resonance and 4DCT simulation images of the patient lying in the treatment position (Figure 2).

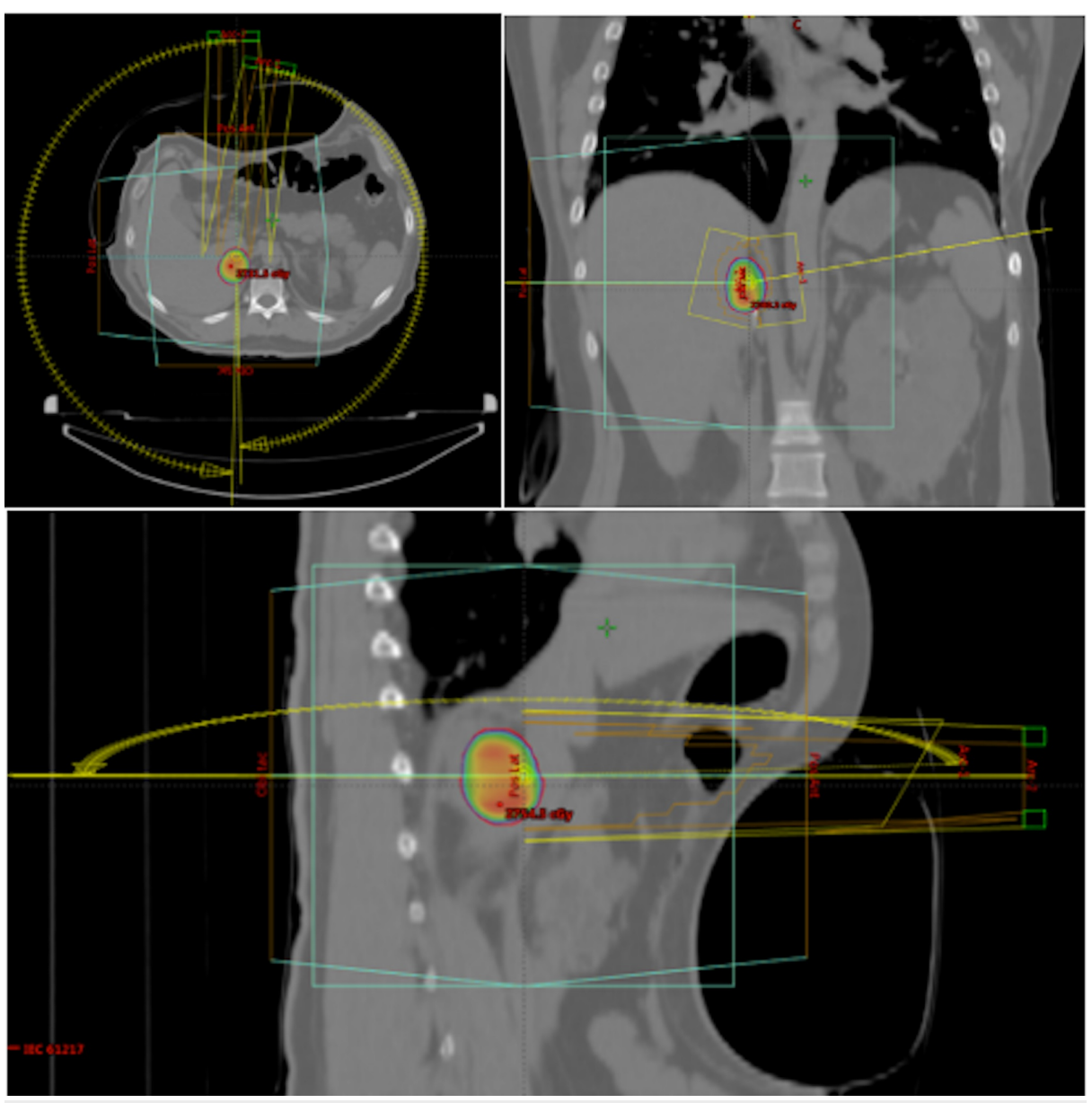

\section{FIGURE 2: 4DCT performed after stabilizing the patient with an} abdominal compressor and a Vac-lock ${ }^{\mathrm{TM}}$ device

The yellow and blue lines represent field disposition and arc conformation, respectively, in the axial, sagittal, and coronal planes (starting with the image on the top-left and moving counterclockwise). The color wash of the circular colored area represents the dose delivered to the target volume.

Treatment volumes were then calculated as follows:

CTV (clinical tumor volume) $=$ GTV (microscopic tumor volume) $+2 \mathrm{~mm}$ volumetric expansion to encompass the macroscopic extent of the tumor

PTV (planning treatment volume) $=\mathrm{CTV}+5 \mathrm{~mm}$ margin

Radiotherapy was performed using two 6-MV non-coplanar VMAT (volumetric modulated arc radiotherapy) half arcs in the reverse direction. The arcs were modified using a multileaf collimator (MLC) to improve PTV (planning tumor volume) coverage and to reduce the dose to healthy tissue. An isotropic convergence beam with inhomogeneous dose distribution was used. Dose optimization was performed with the Photon Optimizer algorithm within the Eclipse ${ }^{\mathrm{TM}}$ system (version 13623) and dose calculation was performed using the Monte-Carlo method. The prescribed dose was normalized to $98 \%$ of the PTV isodose achieving a total of 1696 monitor units, a conformity index of 1.002 , and a homogeneity index of 1.15 . The maximum dose was $114 \%$ in the central part of the volume. The corresponding biological effective dose (BED) was 43.2 Gy. 
The BED is calculated using the following formula: $\mathrm{BED}=$ dose per fraction $\mathrm{x}$ number of fractions $\mathrm{x}(1+$ dose per fraction $/[\alpha / \beta])$ In the formula above, the value of $\alpha / \beta$ is $10 \mathrm{~Gy}$ for tumor tissue.

A Clinac iX ${ }^{\mathrm{TM}}$ linear accelerator was used to deliver the radiation and patient-specific QA (quality assurance) was performed. The daily radiation fractions were administered under continuous blood pressure measurement to evaluate the endocrine function. Simultaneous image verification was performed with an onboard cone-beam CT imaging system. An abdominal compressor was used to improve the reproducibility of the position of the tumor target volume and to limit diaphragm movement. Treatment began on July 24 , 2019, and ended on July 29, 2019, with in-hospital monitoring.

The endocrinology group did the outpatient follow-up after the radiosurgery. Since the patient's symptoms improved and blood pressure stabilized at 125/89 mm Hg (with mean arterial pressure, MAP, at $101 \mathrm{~mm} \mathrm{Hg}$ ), hypertension management with doxazocin, amlodipine, and hydrochlorothiazide was withdrawn and only carvedilol $12.5 \mathrm{mg}$ was administered every 24 hours. There was no additional outpatient follow-up. However, the patient was admitted to the emergency service on August 15, 2019, with a medical history of a maximum-intensity right hemicrania headache radiating to the occipital region and associated nausea, despite being treated with seven morphine drops every eight hours, carvedilol $6.25 \mathrm{mg} /$ day and levothyroxine $50 \mathrm{ug} /$ inter daily. When admitted to the emergency room, the maximal blood pressure levels documented over the patient's medical history (Figure 3) at 148/106 mm Hg (MAP: $120 \mathrm{~mm} \mathrm{Hg}$ ) were observed, with a heart rate of $83 \mathrm{bpm}$, and pulse oximetry $87 \%$. Later, the patient became hypotensive, had signs of dehydration, and was persistently hypoxemic. Therefore, intravenous fluids were ordered, a computed tomography scan of the head and magnetic resonance imaging of the brain were requested, and corticosteroid treatment was started. Despite the treatment, the patient started suffering generalized tonicclonic seizures with supraversion and displayed central and peripheral cyanosis due to hypoxemia (he had $40 \%$ oxygen saturation according to pulse-oximetry). The diagnostic images taken did not show acute ischemic or hemorrhagic events but they did show nodular lesions suspected to be cerebellar hemangioblastomas, with no other significant changes compared to the previous studies. Despite management with phenytoin, the convulsive episodes and hemodynamic instability persisted with a tendency towards hypotension and hypoxemia. The patient was transferred to the resuscitation room. Clinical evaluation during the postictal state detected the absence of vital signs and death was declared on August 16, 2020.

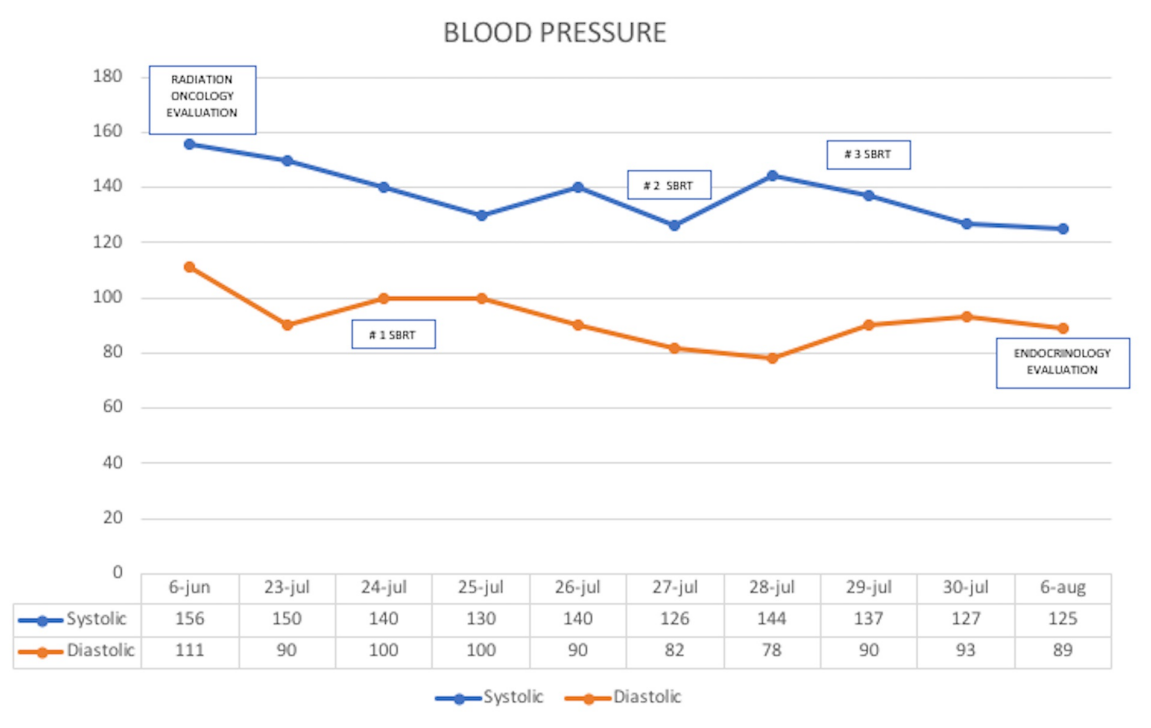

FIGURE 3: Blood pressure kinematics

\section{Discussion}

Pheochromocytoma is a rare neuroendocrine tumor, which can be locally aggressive even when benign. It can be life-threatening due to elevated production of metanephrines by the adrenal glands and their direct impact on the cardiovascular system. The case described constitutes a therapeutic challenge by combining not only an aggressive presentation of the disease, but also a fragile patient with multiple comorbidities and contraindications for surgical and interventional treatments, limited pharmacological alternatives after presenting toxicity, and poor response to medical management.

Despite the scarce information available on radiotherapy treatment in cases of primary adrenal 
pheochromocytoma, there are numerous publications, mainly case studies (Table 1), which support the use of stereotactic body radiotherapy in adrenal metastases [9-13]. These studies report local control and adequate toxicities which justifies the use of this therapy in selected patients. Vogel et al., at the National Cancer Institute, published one of the largest reports on this topic. They found symptomatic control rates of up to $81 \%$ [10]; similarly, Breen et al. reported symptomatic improvement in $94 \%$ of patients treated with EBRT [1].

\begin{tabular}{|c|c|c|c|c|c|c|c|c|c|c|c|c|}
\hline Author & Country & $\mathbf{n}$ & Indication & Technique & $\begin{array}{l}\text { Dose per } \\
\text { Fx/Total Dose }\end{array}$ & $\begin{array}{l}\text { No. } \\
\text { Fx }\end{array}$ & BED & $\begin{array}{l}\text { Local } \\
\text { Control }\end{array}$ & PFS & $\begin{array}{l}\text { OS } \\
\text { (months) }\end{array}$ & Intention & $\begin{array}{l}\text { Follow-up } \\
\text { (months) }\end{array}$ \\
\hline \multirow{3}{*}{$\begin{array}{l}\text { Holy et al. } 2011 \\
\text { [13] }\end{array}$} & \multirow{3}{*}{ Germany } & \multirow{3}{*}{18} & \multirow{3}{*}{$\begin{array}{l}\text { Adrenal Mtx \& } \\
\text { NSCLC Mtx }\end{array}$} & \multirow{3}{*}{ SBRT } & 8 Gy/40 Gy & 5 & \multirow{3}{*}{$\begin{array}{l}43.2-72 \\
\text { Gy }\end{array}$} & \multirow{3}{*}{$77 \%(10 / 13)$} & \multirow{3}{*}{$2-42$} & \multirow{3}{*}{21} & $\begin{array}{l}13 \\
\text { curative }\end{array}$ & \multirow{3}{*}{$12-21$} \\
\hline & & & & & 5 Gy/25 Gy & 5 & & & & & & \\
\hline & & & & & 6 Gy/36 Gy & 6 & & & & & & \\
\hline \multirow[b]{2}{*}{$\begin{array}{l}\text { Vogel et al. } 2014 \\
\text { [10] }\end{array}$} & \multirow[b]{2}{*}{ USA } & \multirow[b]{2}{*}{3} & \multirow[b]{2}{*}{ Adrenal Mtx } & 3DCRT & 1.8 Gy/54 Gy & 30 & & & \multirow[b]{2}{*}{$\begin{array}{l}22.47 \\
\text { (TTP) }\end{array}$} & \multirow[b]{2}{*}{$\begin{array}{l}52.4 \\
\text { (average) }\end{array}$} & \multirow[b]{2}{*}{ Palliative } & \multirow[b]{2}{*}{$\begin{array}{l}52.4 \\
\text { (median) }\end{array}$} \\
\hline & & & & SBRT & $\begin{array}{l}\text { 8-8.5 Gy/24-25.5 } \\
\text { Gy }\end{array}$ & 3 & No data & $86.7 \%$ & & & & \\
\hline \multirow{2}{*}{$\begin{array}{l}\text { Ippolito et al } \\
2015 \text { [14] }\end{array}$} & \multirow{2}{*}{ Italy } & \multirow{2}{*}{188} & Adrenal Mtx \& & SRS & 16-23 Gy & 1 & 22.4- & $\begin{array}{l}1 \text { year: } 44- \\
100 \%\end{array}$ & No & $\begin{array}{l}12(39.7- \\
90 \%)\end{array}$ & \multirow{2}{*}{ Palliative } & \multirow{2}{*}{24} \\
\hline & & & NOCLC IVILX & SBRT & $\begin{array}{l}\text { 3-18 Gy/25-48 } \\
\text { Gy }\end{array}$ & 5 & 130 Gy & $\begin{array}{l}2 \text { years: } 27- \\
100 \%\end{array}$ & dála & $\begin{array}{l}24(13- \\
53 \%)\end{array}$ & & \\
\hline
\end{tabular}

\section{TABLE 1: Treatment doses used with conventional radiotherapy or SBRT to treat metastatic pheochromocytoma}

Fx: Fraction, BED: Biologically effective dose, PFS: Progression-free survival, OS: Overall survival, NSCLC: Non-small cell lung carcinoma, SRS: Stereotactic radiosurgery, SBRT: Stereotactic body radiotherapy, 3DCRT: 3D conformal radiation therapy, TPP: Time to progression, Mtx: Metastases, No. Fx: number of fractions.

This case study adds to the available literature on the efficacy of radiotherapy for the treatment of adrenal pheochromocytomas to relieve symptoms and control blood pressure. Given the fragility and general condition of the patient and unstable blood pressure variables despite multimodal pharmacological management, and after taking into account the effectiveness of stereotactic body radiotherapy in controlling metastatic lesions and the absence of other treatment options, this was considered a highly conformational therapeutic modality that could protect adjacent healthy tissue. A 24 Gy dose was delivered in 8 Gy fractions. In addition, 4DCT simulation, and planning and verification of the dose delivered per fraction were also carried out by onboard Cone-Beam Computed Tomography (CBCT) imaging. Knowing the risk of hemodynamic decompensation and alteration in blood pressure associated with adrenal lesion treatment, continuous hemodynamic monitoring was done by endocrine specialists and anesthesiologists during the delivery of each treatment fraction and afterward.

The patient was hospitalized for follow-up and close surveillance during treatment, and remained asymptomatic during all phases of therapy, with no significant elevation of blood pressure. The patient's hospital discharge was authorized on July 30, 2019, after the radiotherapy ended. During outpatient clinical control, blood pressure was normalized and headache relief was achieved, so the amounts and doses of antihypertensive drugs were reduced. Approximately 20 days after outpatient control the patient was admitted to the emergency room and died of unclear causes. However, during this hospital admission, no figures higher than 148/106 (MAP: $120 \mathrm{~mm} \mathrm{Hg}$ ) were documented, no brain MRI images reported an ischemic or hemorrhagic cerebrovascular event or significant changes compared to a study taken three months earlier. Although the patient displayed hypoxemia and seizures, no exact cause of death was recognized.

\section{Conclusions}

Despite its limited occurrence in the literature, we propose implementing stereotactic body radiotherapy (SBRT) to treat primary adrenal pheochromocytoma in refractory patients, or in patients in whom other treatments are contraindicated, or in patients in whom associated life-threatening conditions are present as was the case in this study. More reviews are needed concerning the safety and effectiveness of SBRT when treating tumors of a similar nature and location. 


\section{Additional Information \\ Disclosures}

Human subjects: Consent was obtained by all participants in this study. Conflicts of interest: In compliance with the ICMJE uniform disclosure form, all authors declare the following: Payment/services info: All authors have declared that no financial support was received from any organization for the submitted work. Financial relationships: All authors have declared that they have no financial relationships at present or within the previous three years with any organizations that might have an interest in the submitted work. Other relationships: All authors have declared that there are no other relationships or activities that could appear to have influenced the submitted work.

\section{References}

1. Breen W, Bancos I, Young WF Jr, Bible KC, Laack NN, Foote RL, Hallemeier CL: External beam radiation therapy for advanced/unresectable malignant paraganglioma and pheochromocytoma. Adv Radiat Oncol. 2017, 3:25-9. 10.1016/j.adro.2017.11.002

2. WHO Classification of Tumours: Pathology and genetics of tumours of endocrine organs . DeLellis RA, Lloyd RV, Heitz PU, Eng C (ed): IARC Press, Lyon; 2004.

3. Maher ER, Webster AR, Richards FM, Green JS, Crossey PA, Payne SJ, Moore AT: Phenotypic expression in von Hippel-Lindau disease: correlations with germline VHL gene mutations. J Med Genet. 1996, 33:328-32. 10.1136/jmg.33.4.328

4. Maher ER, Neumann HP, Richard S: Von Hippel-Lindau disease: a clinical and scientific review . Eur J Hum Genet . 2011, 19:617-23. 10.1038/ ejhg.2010.175

5. Fishbein L: Pheochromocytoma and paraganglioma: genetics, diagnosis, and treatment. Hematol Oncol Clin North Am. 2016, 30:135-50. 10.1016/j.hoc.2015.09.006

6. Lenders JW, Duh QY, Eisenhofer G, et al.: Pheochromocytoma and paraganglioma: an Endocrine Society clinical practice guideline. Int J Clin Endocrinol Metab. 2014, 99:1915-42. 10.1210/jc.2014-1498

7. Leung K, Stamm M, Raja A, Low G: Pheochromocytoma: the range of appearances on ultrasound, CT, MRI, and functional imaging. AJR Am J Roentgenol. 2013 , 200:370-8. 10.2214/AJR.12.9126

8. National Comprehensive Cancer Network. Neuroendocrine and adrenal tumours. Version 2. 2020 . (2020). Accessed: July 24 2020: https://www.nccn.org/store/login/login.aspx? ReturnURL=https://www.nccn.org/professionals/physician_gls/pdf/neuroendoc....

9. McBride JF, Atwell TD, Charboneau WJ, Young WF Jr, Wass TC, Callstrom MR: Minimally invasive treatment of metastatic pheochromocytoma and paraganglioma: efficacy and safety of radiofrequency ablation and cryoablation therapy. J Vasc Interv Radiol. 2011, 22:1263-70. 10.1016/j.jvir.2011.06.016

10. Vogel J, Atanacio AS, Prodanov T, et al.: External beam radiation therapy in treatment of malignant pheochromocytoma and paraganglioma. Front Oncol. 2014, 4:1-8. 10.3389/fonc.2014.00166

11. Pham TH, Moir C, Thompson GB, et al.: Pheochromocytoma and paraganglioma in children: a review of medical and surgical management at a tertiary care center. Pediatrics. 2006, 118:1109-17. 10.1542/peds.2005-2299

12. Hinerman RW, Amdur RJ, Morris CG, Kirwan J, Mendenhall WM: Definitive radiotherapy in the management of paraganglioma arising in the head and neck: a 35-year experience. Head Neck. 2008, 30:1431-8. 10.1002/hed.20885

13. Holy R, Piroth M, Pinkawa M, Eble MJ: Stereotactic body radiation therapy (SBRT) for treatment of adrenal gland metastases from non-small cell lung cancer. Strahlenther Onkol. 2011, 187:245-51. 10.1007/s00066011-2192-Z

14. Ippolito E, D’Angelillo RM, Fiore M, Molfese E, Trodella L, Ramella S: SBRT: A viable option for treating adrenal gland metastases. Rep Pract Oncol Radiother. 2015, 20: 484-90. 10.1016/j.rpor.2015.05.009 